\title{
Imaginarios y géneros discursivos: representaciones problemáticas del periodo colonial en la novela histórica del siglo XIX mexicano
}

\author{
Verónica Hernández Landa Valencia*
}

Resumen:

En este artículo se explora el carácter problemático y contradictorio de la conformación de los imaginarios sobre el pasado colonial en México a partir del análisis de tres novelas históricas publicadas durante la República Restaurada. El análisis contempla la forma en que se entrecruzan imaginarios y géneros discursivos en un solo texto para responder a ciertas necesidades expresivas y explicativas propias del contexto de la República Restaurada que conciernen, por un lado, al imperativo histórico de justificar la independencia frente al pasado colonial y, por otro, al anhelo de consolidar el orden triunfante en 1867. De esta manera, en cada novela, los contenidos revolucionarios entran en tensión con la justificación y reafirmación de un orden establecido.

Palabras clave:

Novela histórica, Siglo XIX, imaginario, Colonia, géneros discursivos, retórica. 
Cuando de imaginarios nacionales se trata, ${ }^{1}$ resulta evidente que entre los más problemáticos y contradictorios, en el caso mexicano, están aquellos relacionados con el pasado colonial. Estudiosos como Leopoldo Zea y David Brading han señalado que en el pensamiento de las élites liberales latinoamericanas del siglo XIX se instauró un hiato que convierte el periodo colonial en una época oscura y opresiva, en oposición a la época independiente; este dificulta pensar ese pasado como parte de un proceso histórico, ya sea orgánico o dialéctico, en un sentido positivo. Así, por ejemplo, la Inquisición española se constituyó imaginariamente en símbolo de la ignorancia, el atraso y la opresión que se atribuía al conjunto del pasado colonial, y tuvo tal impacto que no sería difícil comprobar que ese imaginario, con algunas variaciones, sigue vigente hasta nuestros días.

Sin embargo, resulta necesario advertir que las formas en que se ha representado la oposición entre pasado y presente han cambiado a lo largo del tiempo, pues estas se han vinculado con diversas formas de escritura y corrientes de pensamiento para responder a distintas coyunturas históricas y así han adquirido nuevas significaciones, e incluso se ha intentado tender puentes entre los tiempos, puentes que tampoco están exentos de problemas. En La invención de una legitimidad, Elías José Palti cuestionó la forma lineal y uniforme con que ha sido estudiado el pensamiento liberal del siglo XIX mexicano, al señalar el carácter estratégico y coyuntural y, por tanto, asistemático, a veces hasta aporético, de los discursos políticos. En el capítulo introductorio de su estudio, Palti explica que eso ocurre porque esos discursos tienen un carácter retórico cuya lógica no

${ }^{1}$ Por imaginario se entiende "el lugar en el que se expresan, de manera 'imaginada'. .., es decir, con la ayuda de imágenes y representaciones, las maneras. . . en que una sociedad se ve, se define, se sueña a sí misma” (Pageaux 104). Según las reflexiones vertidas por Cornelius Castoriadis, en La institución imaginaria de la sociedad, no son necesariamente coherentes entre sí ni pertenecen al orden de lo racional, pero actúan en el mundo y tienen una permanencia prolongada en las sociedades. Son flexibles, como un magma, se recomponen y absorben nuevos sentidos debido a su carácter acumulativo. 
se corresponde con el orden de lo racional sino que se deriva de los principios de adecuación y pertinencia en función de los temas abordados en un contexto comunicativo específico.

Desde mi punto de vista, este carácter coyuntural y retórico también se presenta en la literatura mexicana del siglo XIX mexicano, la cual, como lo muestran distintas reflexiones de autores decimonónicos (véase Ruedas de la Serna), tenía una función ideológica y política. Así lo aseguró Ignacio Manuel Altamirano, en 1868:

[La novela] no es solamente un estúpido cuento ... es necesario apartar sus disfraces y buscar en el fondo de ella el hecho histórico, el estudio moral, la doctrina política, el estudio social, la predicación de un partido o de una secta religiosa; en fin, una intención profundamente filosófica y trascendental en las sociedades modernas. La novela hoy suele ocultar la Biblia de un nuevo apóstol o el programa de un audaz revolucionario (39).

Así, en este artículo me propongo mostrar que las representaciones sobre el pasado colonial en las novelas históricas de la República Restaurada tienen un carácter problemático, a veces contradictorio, el cual se explica a partir de la forma en que se yuxtaponen, en una misma obra, diferentes imaginarios y géneros discursivos a partir de los cuales se procura responder a problemáticas distintas.

En cada obra se insertan discursos propios del género deliberativo para explicar la necesidad de la independencia frente al pasado colonial; ${ }^{2}$ en contraste, ciertas formas narrativas procedentes de géneros literarios distintos ofrecen, desde su propia retórica, maneras divergentes de configurar y dar sentido a la sociedad y a los individuos que interactúan en ella, formas que incluso dejan sin justi-

${ }^{2}$ El género deliberativo, desde la época clásica, tenía como propósito argumentar en torno a lo bueno y lo útil, con el fin de persuadir al público para que realizara ciertas acciones que redundaran en el beneficio de la comunidad. Aún en la actualidad es posible observar los vínculos estructurales y funcionales que mantienen cierto tipo de discursos políticos con dicho género. 
ficación cualquier proyecto independentista. En este sentido, los imaginarios sobre el pasado colonial, cuya lógica tampoco procede de lo racional, se constituyen en tópicos de los que echan mano ambas retóricas, y sus efectos en la imagen del mundo que construye el texto literario pueden resultar incluso contradictorios.

Esta propuesta de análisis toma como base tres novelas: Memorias de un impostor y Los piratas del Golfo, de Vicente Riva Palacio, y El pecado del siglo, de José Tomás de Cuéllar. Se inspira en las reflexiones de Bajtín en torno a los géneros discursivos, ${ }^{3}$ así como en el resurgimiento de la retórica como una disciplina que ayuda a estudiar fenómenos discursivos de todo tipo. Procura ofrecer una comprensión más profunda de la construcción narrativa de las novelas históricas de tema colonial, así como contribuir al conocimiento de la forma en que se fueron articulando algunos imaginarios que participan, incluso actualmente aunque con obvias modificaciones, en la conformación de una identidad nacional.

\section{Imaginarios sobre el pasado colonial. Consideraciones preliminares}

El surgimiento del imaginario dicotómico que opuso pasado colonial y presente independiente se vio influido por el pensamiento ilustrado. Este último se caracterizó por convertir la razón en el medio de conocimiento por antonomasia, aquel que permitiría alcanzar el progreso de la humanidad en un mundo cada vez más secularizado. A través de la razón se observaba la realidad y se construían principios y valores cuya validez terminó asumiéndose como universal. Toda conducta humana que no respondiera a los principios racionales llegó a ser calificada en términos de ignorancia y retroceso, y así ocurrió con aquellos elementos del pasado que no

${ }^{3}$ Los géneros discursivos se entienden aquí como formas composicionales, temáticas y estilísticas que involucran modos particulares de significar el mundo, así como ciertos programas de lectura. 
se correspondían con esa racionalidad. La leyenda negra elaborada por ilustrados europeos como Voltaire, la cual presentaba a España como una nación bárbara, inquisitorial y anclada en el pasado, tuvo un papel fundamental en la consolidación del imaginario anticolonial, el cual resultó particularmente útil para justificar la independencia de México una vez que esta estaba consumada.

Es necesario recordar que una de las vertientes del pensamiento ilustrado derivó en una ideología de orden que fue adoptada por los gobiernos del siglo XVIII, incluido el español. El individuo configurado por esta ideología es un ciudadano que se comporta de acuerdo con los principios racionales y morales en beneficio de la comunidad, el cual equivale a su propio bienestar, y no se le atribuyen capacidades revolucionarias. Sin embargo, una consecuencia no prevista por los gobiernos ilustrados fue que la racionalidad que ellos mismos impulsaron se constituyó en la vía de cuestionamiento del orden impuesto.

En algún momento resultó evidente que los intereses del gobierno español no coincidían con los intereses, racionales o no, de ciertos sectores de la sociedad novohispana. ${ }^{4}$ Desde el pensamiento ilustrado que dominaba entre la élite criolla, el cual fue adoptado desde una perspectiva particularmente pragmática, la Independencia solo se legitimaba en la medida en que los intereses y proyectos políticos criollos se revestían de racionalidad, al mismo tiempo que el gobierno español era responsabilizado por el atraso y la superstición que los criollos observaban en su sociedad, omitiendo el hecho de que los propios gobiernos ilustrados españoles habían sido promotores de una transformación política que tenía como objetivo, precisamente, el progreso y la racionalización.

${ }^{4}$ Evidentemente existieron movimientos populares en los que la justificación de la independencia tomó formas distintas a la que predominó entre la élite criolla, pero no serán abordadas en este artículo por no ser los más visibles en el desarrollo del siglo XIX. Fueron los criollos los que consumaron la Independencia y se encargaron de difundir sus imaginarios por distintos medios al resto de la población, de manera que estos predominaron a lo largo del siglo XIX. 
Así se fue fijando en el imaginario una oposición radical entre el presente independiente y el pasado colonial que se definía en términos de progreso y retroceso. Esta fue difundida en los trabajos historiográficos de José María Luis Mora y Lorenzo de Zavala, a quienes David Brading llama los "verdaderos herederos de la Ilustración" (163). Ellos difundieron una filosofía del orden y una visión profundamente jerarquizada de la sociedad que compartió buena parte de la élite letrada mexicana, incluso hasta más allá de la mitad del siglo XIX, la cual influye en la actitud reservada con que, durante décadas, se estudiaron las revoluciones populares como la de Miguel Hidalgo. Esta desconfianza complicaba aún más la explicación del proceso histórico que condujo a la Independencia.

Por otra parte, una nueva conciencia histórica se fue introduciendo en el pensamiento de los mexicanos, la cual tiende a arraigar la identidad nacional en el pasado que se constituye en antecedente del presente; el devenir en la historia se piensa, entonces, como conformador de identidades. Frecuentemente este historicismo está atravesado por una concepción dialéctica en la que el acontecer se presenta como confrontación de fuerzas, una de las cuales está destinada a triunfar, y es la que prefigura el futuro; en otros casos, la historia se manifiesta como un organismo en desarrollo.

La aparición de esta nueva conciencia histórica resultaba problemática en México en tanto que ya se había instaurado en el imaginario la ruptura con el pasado colonial. Es así que en la literatura se narran historias ambientadas en la Colonia donde personajes criollos representan la identidad nacional y son objeto de algún tipo de persecución social o inquisitorial. Es el caso de obras como El visitador (1838), de Ignacio Rodríguez Galván, y El criollo (1839), de José Ramón Pacheco. Aunque esos personajes sugieren la confrontación de fuerzas históricas, no se rebelan contra el sistema y mueren al final de los relatos sin dejar descendencia, de manera que no se materializa una concepción dialéctica u organicista del acontecer; el espacio narrado es apenas un escenario en que se desarrolla una trama trágica, por lo que es difícil reconocer a través de él el paso del tiempo, la historicidad del mundo representado. Así, la relación entre los tiempos queda en el nivel de lo simbólico mientras que, 
a nivel narrativo, se mantiene la oposición. De hecho, estas tramas trágicas introducen la circularidad en la imagen del tiempo, ya que reafirman el orden de mundo que ha fijado el destino de los protagonistas de antemano, y estos últimos, condenados a la muerte, no pertenecen a una historia abierta hacia el futuro.

A la par de la nueva conciencia histórica se introduce también cierta concepción romántica del hombre como un individuo rebelde que lucha por la satisfacción de sus ideales, por alcanzar y defender su libertad, sus ambiciones o sus deseos a toda costa, ideales que no necesariamente se corresponden con los de la sociedad de la que forma parte y de la que a veces se exilia o la combate; un hombre que, si se empeña en sus ideales, tiene la posibilidad de transformar su realidad. Precisamente en la época de la Guerra de los Pasteles surgen poemas que exaltan a héroes libertadores y rebeldes contra la invasión, tales como "El soldado de la libertad" (1838), de Fernando Calderón, y "Profecía de Guatimoc" (1839), de Ignacio Rodríguez Galván. El imaginario libertario florece ante la amenaza extranjera, pero, hasta donde sé, en ese momento no se asociaba con el pasado propiamente colonial, y no implicaba la rebelión de una sociedad frente a su propio gobierno.

Aparentemente, es hasta la novela histórica La hija del judio (18481949), de Justo Sierra O’Reilly, cuando llega a su máximo esplendor la conjunción entre historicismo y romanticismo: los protagonistas están situados en un espacio-tiempo perfectamente identificable como colonial gracias a las abundantes descripciones, a las referencias históricas, y debido a que sus acciones están condicionadas por la circunstancia histórica; se rebelan contra los mandatos de una autoridad arbitraria y corrupta, participan en la resolución dialéctica del conflicto de fuerzas que se manifiesta en la vida pública y, aunque unos se exilian para protegerse de la persecución inquisitorial que, a pesar de todo, amenaza su vida privada, años después sus descendientes pueden regresar a Yucatán. En esta novela la oposición radical entre pasado y presente desaparece porque al interior de la diégesis colonial se mueven distintas fuerzas, algunas de las cuales prefiguran el presente independiente y triunfan al final de la historia. Lo trágico y lo cómico, mixtura propia de la novela moderna, 
se conjugan de manera que se favorece la solución del conflicto en beneficio de los protagonistas. Esta casi perfecta conjunción entre historicismo y romanticismo se presenta en una novela, escrita por un yucateco, que exalta la rebeldía y justifica la independencia en el momento en que Yucatán se había independizado de México.

A partir de este breve panorama se puede advertir que la forma en que se articulan los imaginarios sobre el pasado parece muy ligada a una circunstancia histórica, a la forma en que se fueron desarrollando los acontecimientos en México. Los ejemplos vistos aquí dan la impresión de que la literatura y los imaginarios fueron evolucionando progresivamente. Sin embargo, al estudiar las novelas históricas de tema colonial publicadas en la República Restaurada, he advertido que esa imagen de evolución se rompe: la oposición entre los tiempos en términos de progreso y retroceso se manifiesta nuevamente; la historia no siempre parece antecedente del presente, y así se desestabiliza la historicidad del pasado representado. A nivel del discurso del narrador, se sostienen ciertos imaginarios; en contraste, a nivel de la trama o del discurso de otros personajes, influidos por géneros literarios y no literarios diversos, resuenan otros imaginarios que dificultan la interpretación del texto; aquí el individuo con iniciativa se vuelve un elemento problemático.

Quizás una buena parte de la literatura mexicana presente estas características; no obstante, para probarlo hace falta estudiar una gama más amplia de textos y ese es un trabajo que excede por mucho las intenciones de este artículo. Por ahora, me centraré en tres novelas publicadas en la República Restaurada que permiten evidenciar la relación compleja que se establece, en ese contexto, entre imaginarios sobre el pasado colonial y géneros discursivos.

\section{La República Restaurada como contexto de enunciación}

Sin pretender detenerme demasiado en el contexto histórico de la República Restaurada, en la medida en que es la coyuntura histórica la que explica la peculiar forma de representar el pasado, es importante señalar dos aspectos que fungirán como ejes problemáticos 
que enmarcan el análisis de las novelas. En primer lugar, la República Restaurada representa el fin de las grandes guerras civiles y los conflictos internacionales que desestabilizaron al país durante más de cincuenta años. En este sentido, es un periodo en que se busca la estabilidad a toda costa, y por eso la palabra "orden", frecuentemente como condicionante del progreso, aparece una y otra vez en los periódicos de un país que no se encontraba totalmente pacificado; aún se registraban levantamientos aislados y la seguridad pública constituía un problema que demandaba soluciones urgentes.

Con el fin de estabilizar a la nación, las políticas del gobierno liberal de Benito Juárez se inclinaban a "diferir prácticas institucionales y derechos civiles en beneficio de la estabilidad y el desarrollo" (Knight 61). ${ }^{5}$ En este sentido, son conocidos los intentos de Juárez por fortalecer el poder Ejecutivo y suspender temporalmente las garantías individuales. ${ }^{6}$ Es decir, el principio de la libertad individual, y de su defensa, retrocede ante la necesidad de estabilizar y pacificar definitivamente al país. Incluso llega a suceder que -en esta búsqueda de anclajes en el pasado que el nuevo historicismo había desatado- se recuerde a gobernadores ilustrados como ejemplos del

${ }^{5}$ Cabe recordar que el liberalismo pasa por distintas etapas. Alan Knight las define de la siguiente manera: "el liberalismo constitucional", que estuvo marcado por una creencia ciega en que las reformas políticas transformarían a la sociedad; el "liberalismo institucional" que apoyaba cambios más radicales y para ello requería una intervención más activa por parte del Estado, que tendía a limitar o coartar algunas libertades individuales, y el "liberalismo desarrollista" (61), que se define arriba. Desde aquí se puede advertir que el concepto de libertad, en lugar de ampliarse, pasa por un proceso inverso. Otros autores, como Elías José Palti, se inclinan a mostrar un proceso todavía más desigual, detectan incluso variables en una misma época o en un mismo autor, de manera que los términos evolución, progresión o retroceso resultan inadecuados para explicar lo que ocurre en el pensamiento y las políticas mexicanas. En mi tesis "Los tiempos de la historia: la representación de la Colonia en tres novelas históricas de la República Restaurada" se puede advertir también que dos autores liberales, en una misma época, presentan formas de conceptualizar el pasado colonial considerablemente distintas.

${ }^{6}$ Los debates que generaron las iniciativas de Juárez se pueden rastrear en periódicos como El Siglo Diezy Nueve, sobre todo a finales de 1868 y principios de 1869. 
orden al que se quería encaminar el propio presente. ${ }^{7}$ Resulta particularmente sintomático que, en 1868, ciertos miembros del Ayuntamiento de la Ciudad de México proyectaran colocar el retrato del segundo conde de Revillagigedo en la sala del Cabildo y erigirle una estatua. Sin embargo, esta iniciativa provocó reacciones que evidenciaron que la relación con el pasado colonial era particularmente conflictiva. Según El Constitucional, el proyecto era "anticonstitucional, y contrario a la dignidad y al decoro del pueblo mexicano, porque aquel virrey, por bueno que fuera, era uno de los opresores de México, o representante de ellos" (cit. en La Iberia, 20 de marzo de 1868, p. 3).

Asimismo, se trata de un periodo de consolidación y reafirmación del gobierno liberal cuyas políticas, en los últimos veinte años, habían puesto particular énfasis en la desamortización de bienes eclesiásticos y en la reducción de la influencia política de la Iglesia para así fortalecer al Estado como único poder. De igual manera se procuraba reducir la oposición política de grupos conservadores que se habían aliado a la Iglesia. ${ }^{8}$ Es así que en periódicos como El Siglo Diezy Nueve, El Monitor Republicano, El Constitucional y La Orquesta se pueden rastrear debates en torno al papel de la institución eclesiástica y de los antiguos miembros del partido conservador en el nuevo orden. Estos debates son particularmente álgidos entre 1868 y principios de 1869, luego pierden intensidad, pero resurgen cada cierto tiempo, al menos hasta 1872 .

${ }^{7}$ Revillagigedo es citado como ejemplo por periódicos de filiación política diversa. Véase por ejemplo El Monitor Republicano (27 jun. 1868: 1), La Orquesta (23 jul. 1868: 1) -en esta publicación fungía como redactor Vicente Riva Palacio-, y La Revista Universal (18 oct. 1869: 1).

${ }^{8}$ Se emplean aquí los términos "conservador" y "liberal" solo con la finalidad de agilizar la exposición en la identificación de ciertos grupos políticos, sin que por eso se asuma que dichos grupos sostuvieran una ideología unificada y claramente delimitable. El concepto "conservador", al igual que el de "liberal", han sido problematizados por estudiosos como Edmundo O'Gorman, Brian Connaughton, Erika Pani y Elías José Palti, y a ellos remito al lector para profundizar en el tema. 
Frecuentemente, conservadurismo e Iglesia son equiparados en el imaginario, y también se presenta una asociación metonímica entre ellos y el pasado colonial, el cual sigue manteniendo una carga simbólica asociada con el oscurantismo, la ignorancia y la represión, sobre todo en lo que respecta a la institución religiosa. La Colonia se convierte en ejemplo a través del cual se procuran evidenciar las virtudes del reformismo republicano, y así se reactiva la oposición, de origen ilustrado, entre presente y pasado en términos de progreso y retroceso, que ahora aglutina también la dicotomía liberalismo / conservadurismo. ${ }^{9}$

Búsqueda de orden y afianzamiento de un proyecto político son tendencias muy marcadas en la República Restaurada, e intervienen en los debates sobre el pasado y en la representación de la Colonia en la novela histórica. En este sentido, no hay que olvidar, tal como

9 Paralelamente, la defensa de los conservadores se manifiesta en las páginas de La Revista Universal, donde, por un lado, se cuestionan los imaginarios sobre el oscurantismo del pasado colonial, o se matiza el imaginario sobre la Inquisición ubicándola históricamente en un contexto en que las prácticas de la tortura eran comunes también a los tribunales civiles, generando así un distanciamiento que favorece la normalización de la mirada sobre el pasado y diluye las dicotomías sobre las que se construyen los imaginarios sobre el presente; y, por otro lado, se defiende la buena voluntad de los llamados conservadores para colaborar con el orden en el presente. Frecuentemente, la contextualización histórica se emplea también como mecanismo para cuestionar el protestantismo por el que algunos liberales sentían admiración. En este sentido, se muestra que los tribunales protestantes también quemaban a las supuestas brujas y herejes. Todo ello se puede observar en la crítica que Mariano Dávila hizo a Monja y casada, virgen y mártir, en unas "Breves observaciones" que se prolongaron desde diciembre de 1868 hasta marzo de 1869, publicadas en La Revista Universal. Esa misma tendencia se puede advertir en la novela histórica Un hereje y un musulmán (1870), de Pascual Almazán (919-922), quien se encontraba exiliado en Puebla por haber colaborado con el gobierno de Maximiliano de Habsburgo. Es importante tener presentes estas respuestas pues si bien es cierto que el imaginario en el que me he centrado en este artículo, el que terminó por predominar en el imaginario nacional, fue el difundido por los liberales, los imaginarios novelescos fueron configurados tomando en cuenta los debates propios de la época, se constituyen en una respuesta frente a los mismos. 
lo ha señalado Noé Jitrik, que la novela histórica se constituye en una búsqueda de respuestas a las inquietudes e interrogantes del presente (19), y resulta sintomático que en este periodo se publicaran más novelas de tema colonial que en cualquier otro momento del siglo XIX. En el periodo que abarca de 1868 a 1872, el magistrado de la suprema corte, Vicente Riva Palacio, publicó cinco novelas históricas a propósito de la Colonia. El escritor José Tomás de Cuéllar, afín al partido liberal -aunque opositor a las políticas de Juárez que tendían a fortalecer y ampliar la capacidad de acción del presidente, tales como la reelección de 1868 y la suspensión temporal de las garantías individuales en 1869-, publicó El pecado del siglo en 1869. En todas ellas, el formato por entregas, distribuido por periódicos de filiación política liberal, favorecía el debate y la difusión de ciertas posturas ideológicas.

José Ortiz Monasterio ha señalado que Vicente Riva Palacio representa en sus novelas episodios en que percibe "tentativas de libertad ... afanes de levantar a la tierra contra el dominio español" ("Preceptiva e historia" 183). De hecho, su novela Memorias de un impostor (1872) se centra en Guillén de Lampart (1611-1659), uno de los personajes actualmente ubicados en el monumento a la Independencia; en el "Prólogo del autor" de dicha novela se dice que Lampart era un "irlandés que había querido hacer independiente a la Nueva España” (XIV-XV). De manera semejante, en Los piratas del Golfo (1869), el pirata Morgan se muestra en un principio como libertador de América: "Yo he viajado por todas esas colonias que Europa posee en tierra firme; yo he visto la tiranía y la esclavitud dividirse a los habitantes; yo he vislumbrado para esos pueblos una era de libertad, y tengo la convicción de que yo puedo hacer que luzca ese día de emancipación" (1: 158). Por su parte, en El pecado del siglo aparece Francisco Primo de Verdad (1760-1808), quien, en la dedicatoria de la novela, es identificado como la "primera víctima de las ideas de independencia nacional" (Cuéllar 3).

Si se atiende a estas citas, pareciera que la representación del pasado en las novelas se centra fundamentalmente en la exaltación de la rebeldía contra el gobierno colonial, de manera que se reactiva el imaginario libertario que se desarrolló en las primeras dos décadas 
del siglo XIX; cada uno de los personajes arriba mencionados adquiere un carácter heroico que se asocia claramente a sus tentativas de independizar a México de España. Sin embargo, desde mi punto de vista, este imaginario entra en tensión con otros que resultan mucho más acordes con las preocupaciones propias del periodo de la República Restaurada y que frecuentemente se manifiestan en la estructura profunda de las novelas.

Como se ha dicho previamente, la libertad individual se constituyó en un problema en la medida en que las guerras civiles que precedieron a la República Restaurada fueron motivadas por intereses de grupo y causaron una inestabilidad política y social que se prolongó por casi cincuenta años. En la época en que se escribieron las novelas aún se registraban levantamientos aislados contra el gobierno y el país enfrentaba frecuentes robos y asaltos, tanto en los caminos como en las ciudades. Por lo tanto, las iniciativas individuales rebeldes a un gobierno o a un orden institucional debían provocar desconfianza. En este marco, la exaltación de la rebeldía, aun cuando esta se ubicara en un pasado remoto, podía resultar contraproducente: el héroe libertario era capaz de inspirar aquellos que leían historias sobre el pasado para pensar su presente.

\section{Memorias de un impostor y el héroe problemático}

Desde el Prólogo de Memorias de un impostor se puede detectar una actitud ambigua frente al personaje de Guillén de Lampart como héroe rebelde: así como algunas veces aparece como un ser que luchó por la independencia del país, en otras ocasiones el narrador destaca la ambición personal y el ego desmedido de un "irlandés que quiso coronarse rey de México" (XIV). El mismo título de la novela, Memorias de un impostor. Guillén de Lampart, rey de México, evidencia el carácter engañoso de un personaje que se hace pasar por lo que no es.

El narrador expresa una actitud reservada frente a dicho personaje y no toma partido cuando contrasta las aseveraciones de Lampart con la opinión que sobre él manifiestan los inquisidores, 
ambos plasmados en los documentos del Santo Oficio que se incluyen en el apéndice de la novela. Dice el narrador: "Opinaron los inquisidores que toda esa historia era un tejido de mentiras y falsedades inventadas por don Guillén; pero como nada prueba que esta historia fuera lo que pensaban los inquisidores, y verdad como sostenía don Guillén, el autor de este libro no se atreve a inclinarse ni a una ni a otra opinión” (2: 113). En ocasiones incluso sugiere que sí hay un cierto grado de falsedad en Lampart, debido a su carácter vanidoso:

don Guillén ... no solo trataba de conseguir la ayuda de Diego en su empresa, sino que lo impulsaba a hacerla, el deseo de aparecer ante [los] ojos [de Diego Pinto] como un hombre de alta importancia política y social.

Mísera condición humana que busca el aplauso en todos los casos, y que procura la adulación y lisonja en todas partes (2: 128).

La misma estructura novelesca se alimenta de distintos géneros discursivos que entran en tensión al interior del texto, creando sentidos múltiples. Por un lado, las actividades de Lampart se estructuran de acuerdo a la novela de aventuras costumbrista (véase Bajtín, "Las formas del tiempo" 263-82), en que el personaje aparenta ser un noble de alta influencia social, y así se introduce en los salones donde se evidencian las bajas pasiones y egoísmos que corroen a la sociedad. Esas intrigas de salón derivan en acusaciones injustas y en el posterior derrocamiento del virrey marqués de Villena, el cual, como "era incapaz de traición o felonía" (2: 38), al final "consiguió probar plenamente su inocencia” ante el rey (2: 292). Desde esta perspectiva, no se justifica un proyecto independentista; al contrario, el discurso del narrador se posiciona a favor del gobernante. La estructura narrativa muestra que las prácticas políticas de ciertos sectores amenazan el orden público, y esta forma de representación tiene mucho sentido si se atiende a las preocupaciones por consolidar el sistema político y pacificar a la sociedad durante la República Restaurada. 
No obstante, sí se hace presente un discurso a favor de la independencia, pero este está desvinculado del movimiento social que termina por derrocar al virrey y, de hecho, presenta problemas en lo que respecta a su articulación narrativa. Se expresa a través de la retórica propia del género deliberativo, en los discursos que tienen lugar en las reuniones secretas de los conspiradores presididos por Lampart, en los capítulos titulados "Los misterios de Urania" y "Los planes de don Guillén" (1: 119-32). Ahí la necesidad de la independencia no se atribuye a los errores del gobierno español sino que la Iglesia, representada por la Inquisición, aparece como la única responsable de la ignorancia que entorpece el progreso científico en la Nueva España:

Nosotros somos los discípulos de Copérnico, y continuamos su obra; nosotros creemos que el Sol es el centro de su sistema, que la Tierra gira en su derredor... .

Y por eso se nos persigue; y para estudiar eso tenemos que reunirnos ocultamente como criminales. ...

Y esta persecución se extiende casi por toda la tierra. Galileo, perseguido y encarcelado por la Inquisición en Roma el año de 1633, sólo por tener la misma opinión que nosotros y por haberla defendido en sus escritos, iluminando al mundo con la clara luz de su inteligencia, ha tenido que abjurar, contra su conciencia, eso que llaman sus errores. ...

Al trabajar en la obra de la ciencia, que tiene por objeto colocar al Sol en el trono de que quisieron derribarle la ignorancia y el fanatismo, tuvimos nuestra palabra de reconocimiento y de orden: Helios, es decir el Sol. ...

Pero Helios, es luz, vida, libertad: nosotros necesitábamos la libertad para el Anáhuac y para sus hijos, y nuestra empresa se hizo de redención (1: 124-25).

Aquí se reactiva el discurso ilustrado que justifica la Independencia en la medida en que una parte del sistema colonial se figura como un obstáculo para el progreso, y al mismo tiempo se legitima el proceso de secularización que llevaban a cabo los reformistas 
desde mediados del siglo XIX. Sin embargo, las ideas volcadas en estos capítulos tienen poco que ver con el desarrollo de los acontecimientos en el conjunto del relato, en que la mayoría de los criollos conspiran para obtener ventajas personales. De esta manera, se evidencia la imbricación de imaginarios que hacen eco de las distintas preocupaciones del presente de la República Restaurada, las cuales tienden a arraigarse en la representación del pasado, aunque no se conjugan en una totalidad de sentido.

Al final de la novela, en el apéndice, aparece otro género discursivo que hace más ambigua la imagen de Guillén de Lampart. Se trata de documentos inquisitoriales en que Lampart es descalificado por mentiroso, ególatra y ambicioso, los cuales no dejan de influir en la imagen del personaje. Ciertamente, aun en esos documentos, destaca el hombre de conocimiento profundo en distintas ciencias, el cual se atrevió a desafiar la ignorancia y el fanatismo representados por la Iglesia y sus inquisidores, pero también queda a la vista la ambición individual, la falsedad en las declaraciones y la impostura, las cuales oscurecen la imagen del héroe independentista.

Finalmente, cabe advertir que la personalidad y el destino del héroe son tejidos por una trama trágica en su sentido más clásico: un presagio anuncia la fatalidad que regirá la vida del personaje y el desarrollo de los acontecimientos confirma dicho presagio, para el que no existe escapatoria. Guillén de Lampart asegura que, al nacer, su horóscopo le predijo:

felicidad, riqueza, honores valor, ciencia ... Una noche, quizá ese mismo día, mi madre soñó que el diablo llegaba junto a su lecho en la figura de un caballero vestido de color de fuego, y que le decía: "Yo soy el monarca de las tinieblas y del mal: el que todo lo puede ha bendecido a tu hijo y le ha dado sus dones; quiero darle yo también los míos: yo le señalaré para darle el poder del amor sobre los corazones de las mujeres; feliz será con ellas como ningún otro, pero esto le apartará de otros caminos y le traerá a mi reino". Y al decir esto, el diablo 
puso su dedo sobre mi frente, dejándome en ella una mancha rojiza (1: 83). ${ }^{10}$

Las mujeres, en efecto, son la debilidad de Lampart y es la marca del diablo la que sella su destino, la que lo hace traicionar a sus enamoradas, una de las cuales, deseosa de venganza, denuncia la conspiración de Lampart a la Inquisición.

Este tipo de trama en que se manifiesta la ironía del destino reafirma la imagen de que el hombre está sometido a fuerzas más allá de su comprensión, recalca la futilidad de los intentos por cambiar su circunstancia, de manera que sería la menos adecuada para exaltar movimientos independentistas o revolucionarios, pero sí la más a propósito para promover resignación entre los hombres ante un orden de mundo particular. ${ }^{11}$ Así, la ciencia y el progreso se mantienen en el imaginario como valores del presente que se oponen al pasado en que dominaba la Inquisición -y todos los elementos que imaginariamente han sido asociados a ella-, pero al mismo tiempo un tipo de narrativa que reafirma el orden establecido previene al hombre contra cualquier intento revolucionario.

Estas formas de representar el pasado entran en tensión y crean contradicciones que vuelven más complejo y problemático el imaginario sobre el pasado. La Independencia, como un suceso histórico que rompió las ataduras con el gobierno español queda sin explicación e incluso resulta injustificado si se atiende a la representación del virrey como un personaje inocente frente a las acusaciones que le dirige la sociedad. La oposición entre pasado y presente se relaciona esencialmente con el papel dominante de la Iglesia, pero su relación con un proyecto independentista no logra articularse narrativamente; en contraste, se manifiesta una insospechada empatía hacia la figura del gobernante colonial.

${ }^{10}$ Las cursivas son mías.

${ }^{11}$ Tal como advierte Hyden White, la trama trágica implica una concepción particular del tiempo que se caracteriza por "una persistente estructura de relaciones o un eterno retorno de lo mismo en lo diferente" (21). 


\section{Un mundo sin héroes, un mundo de orden: El pecado del siglo}

$\mathrm{Al}$ igual que ocurre en Memorias de un impostor, en El pecado del siglo el sentido de la independencia significa una liberación frente a la influencia de la Iglesia sobre las conciencias. En este último caso, además, aparece como una independencia prácticamente institucionalizada. Francisco Primo de Verdad se presenta como un hombre ilustrado asesor del segundo conde de Revillagigedo, virrey de la Nueva España que, según el narrador de la novela, fue enviado por Carlos III, en 1789. ${ }^{12}$ Los encendidos discursos de Primo de Verdad en contra de la Iglesia se dirigen sin tapujos a un sacerdote:

... usted menos que nadie debería sorprenderse al contemplar los frutos de la tiranía religiosa. El despotismo ha llenado el mundo de mártires y esclavos, de ignorantes y seres abyectos, pero en la terrible lección de la desgracia, se levantan un día los oprimidos y rompen sus cadenas: tiempo vendrá en que el clero católico predominante y omnímodo, sienta rugir el volcán bajo el pedestal de su grandeza (142).

Igual que en Memorias de un impostor, se echa mano del género deliberativo para demostrar la responsabilidad que tiene la Iglesia en la

${ }^{12}$ En realidad, Revillagigedo fue enviado por Carlos IV y no encontré ningún registro de que Primo de Verdad conociera directamente a Revillagigedo; evidentemente se trata de una licencia poética que permite concentrar en una sola historia a personajes que resultan representativos de un periodo. En la misma época en que se escribió El pecado del siglo, Primo de Verdad es asociado con la rebelión contra el gobierno español. Así ocurre en el relato que sobre él escribe Manuel Payno en El libro rojo: "con todo el fuego de un republicano; habló de patria, de libertad, de independencia, y por último proclamó allí mismo, delante del virrey y del arzobispo y de la audiencia, y de los inquisidores, el dogma de la soberanía popular" (303). No obstante, también aquí se manifiesta una representación problemática del héroe independentista debido a que todas las narrativas históricas de ese libro están marcadas por un sino trágico. Representan los fracasos, las derrotas, las muertes sangrientas de distintos personajes de la historia de México, que no aparecen enlazados narrativamente, de manera que se trata de relatos más cercanos al mito que a la Historia. 
ignorancia de la sociedad y la necesidad de educar a la sociedad de otra manera, acorde con principios de orden y secularización. Estos discursos retóricos de carácter argumentativo, que se repiten en distintas novelas de la época, ${ }^{13}$ son sintomáticos de las preocupaciones del presente, propias del reformismo secularizador de la República Restaurada, que detonan la escritura del pasado.

En el caso de El pecado del siglo, las tendencias secularizadoras se arraigan en el gobierno ilustrado promovido por los borbones, de manera que la necesidad de un movimiento revolucionario que derroque al gobierno español queda sin explicación. De hecho, no se hace mención de la Revolución francesa, que tuvo lugar en el mismo año en que se ubica la diégesis de la novela. En contraste, se trata de una obra que enfatiza la influencia nefasta que ejercen los individuos con iniciativa en el orden social.

La novela se caracteriza por un didactismo costumbrista propio de narrativas ilustradas como la de Don Catrín de la Fachenda (1819), de José Joaquín Fernández de Lizardi, en que los personajes se constituyen en tipos morales y sociales, a través de los cuales se ejemplifican conductas virtuosas y viciosas de distintos grupos de la sociedad, y así se promueven ciertos modelos de comportamiento entre los lectores. En esta clase de relatos la sociedad aparece como responsable de los problemas que afectan al mundo, de manera que no se propone un cambio en el sistema político sino en las costumbres.

En este sentido, cabe advertir que la influencia del didactismo costumbrista en una novela histórica crea una paradoja: un relato con fines pedagógicos se dirige siempre a la sociedad del presente, y los sucesos representados, ubicados en cualquier tiempo, se constituyen en espejo de dicha sociedad. Este tipo de relatos son particularmente afines a la visión ciceroniana de la historia como maestra de la vida, por lo que resultan problemáticos cuando una nueva

${ }^{13}$ Véase, además del conjunto de las novelas de Riva Palacio, Un hereje y un musulmán, de Pascual Almazán, El Cerro de las Campanas, de Juan A. Mateos y Los mártires del Anábuac, de Eligio Ancona. 
comprensión de la historia ha difundido la idea de que el pasado es origen del presente pero esencialmente distinto de él.

En la novela de Cuéllar no se encuentran descripciones que evidencien la historicidad del mundo narrado y puedan invalidar la función didáctica y moralizante del texto; así, por ejemplo, el espacio funge como recurso para reafirmar las cualidades o defectos morales que representan los personajes, de manera que facilita la lectura alegórica.

Sin embargo, la imagen esencialista del espacio y los personajes-tipo entra en tensión con los comentarios del narrador y de Primo de Verdad, por medio de los cuales se construye la idea de que el mundo se ha ido modificando y el pasado se constituye en antecedente del presente. El discurso de Primo de Verdad previamente citado anticipa el tiempo de la Reforma en que el poder de la Iglesia se vio fuertemente cuestionado; por su parte, el narrador usa enfáticamente el tiempo pasado para referirse a la época en que dominaba la Iglesia:

El clero católico, en el auge de su preponderancia sobre la Tierra, logró reasumir la vida en el culto. ... .

La libertad de la conciencia era el camino del quemadero.

La libertad civil era reputada como blasfemia" (31).

En este juego ambivalente entre didactismo e historicismo el narrador llega a delatarse y muestra que la función fundamental es de carácter didáctico y se dirige claramente a los lectores de la República Restaurada cuando usa el tiempo presente para reflexionar, en un discurso más cercano a la retórica deliberativa que a la judicial, en torno a los pecados que cometen los personajes en el relato:

¿Hasta cuándo cesará la herencia fatal que no es el pecado de un hombre, que no es la voluntad de un ser rebelde quien lo engendra, un pecado que no es ni la sedición ni la desobediencia, un pecado sordo que se transmite, que pasa de conciencia a conciencia, y que inocula a los hijos con la sangre de los padres, ... vuela sordamente inoculando, matando 
y subyugando a seres que medio ven, que medio oyen, que medio entienden y que bajan a la fosa con su absolución y su pecado, a despecho de la luz de la civilización y del progreso humano? (128).

De esta manera, al mismo tiempo que las tendencias secularizadoras del presente parecieran arraigarse históricamente en el pasado, en la figura y voz de Primo de Verdad, la difusión, a través del relato del pasado, de principios que se asumen válidos para todos los tiempos, para ordenar a la sociedad del presente, diluye la historicidad de ese mismo pasado.

Aunque en esta novela se contraponen personajes que se pueden asociar con distintas fuerzas de la historia, más allá de las críticas que expresa Primo de Verdad frente a un sacerdote, no hay confrontación en absoluto. De hecho, en tanto que personajes-tipo, representan, sobre todo, ideas, y no caracteres individualizados que puedan establecer entre sí relaciones humanas e históricas. Los personajes se pueden dividir en dos grupos: ilustrados progresistas y pecadores que contribuyen al retroceso. Entre los segundos encontramos, por un lado, personajes que actúan mal debido a la educación religiosa que censura Primo de Verdad; por otro, criminales cuyas historias recuerdan ciertos relatos populares recuperados por el romanticismo. Entre ellos no se establece una relación causal sino que sus aventuras se presentan yuxtapuestas a lo largo del relato.

En el caso de los personajes que reciben una mala educación religiosa, ellos no representan ninguna amenaza al orden público, sobre el cual la Iglesia no ejerce mayor influencia; su educación simplemente los lleva a una vida miserable. Es así que el discurso independentista que se le atribuye a Primo de Verdad es, fundamentalmente, de carácter moral y atañe al conjunto de la sociedad pero no al orden político e institucional del que Primo de Verdad forma parte.

Por su parte, las acciones de los personajes que recuerdan a narraciones populares recuperadas por el romanticismo sí afectan el orden público. En su caracterización interviene el didactismo costumbrista que los despoja del sentido heroico que el romanticismo atribuyó a los protagonistas originales, para convertirlos en 
personajes estereotipados que son objeto de censura moral. En la historia de Margarita y Felipe encontramos claras reminiscencias de Fausto, pero en lugar de un héroe que ambiciona el conocimiento o el poder de dominar a la naturaleza y es redimido por el amor, encontramos un seductor inmoral, el estereotipo del hidalgo, que solo desea dinero y comodidades, y al final recibirá su castigo en el cadalso mientras Margarita queda recluida en el convento. La vida de la bruja Teodora y de su hijo Baltasar recuerda a las historias del moro expósito y la mulata de Córdoba, pero en vez de un hijo heroico dispuesto a vengar a su padre, el de Teodora resulta ser un ladrón corrompido, y ella, despojada de poderes mágicos, no pasa de una conocedora de efectos químicos y herbolaria que se aprovecha de las supersticiones de la sociedad para ganar dinero y encontrar a su hijo. Todos estos personajes buscan satisfacer deseos que los llevan a la perdición.

En cambio, los personajes que representan los valores ilustrados no ambicionan nada, no se apasionan por nada. Ellos asumen el papel que les corresponde en la sociedad y se limitan a cumplirlo: Carlos estudia medicina, espera ejercerla y casarse con su novia para formar una familia. Primo de Verdad cumple su función como consejero de Revillagigedo y ofrece orientación moral a quien la solicita. El virrey, tal como le corresponde a un gobernante ilustrado, impone orden en todos los ámbitos de la vida: además de proyectar una serie de reformas en la administración y de procurar "la decencia pública" (232), "dictó sus primeras medidas para el establecimiento de la policía de seguridad" (241), de manera que al final del relato logra atrapar a los asesinos de la familia Dongo. Son estos personajes, aquellos que carecen de ambiciones personales y ejercen su libertad para actuar de acuerdo con lo que la sociedad espera de ellos, sin amenazar el orden establecido, los que sobreviven al final de la novela y los que se proyectan como el ideal de la sociedad en el contexto ordenador de la República Restaurada.

En esta novela sí es posible encontrar una forma narrativa dominante, el costumbrismo didáctico de corte ilustrado. Sin embargo, a través de ella se constituyen distintas historias que no tienen relación directa entre sí, sino que ayudan a exponer distintos problemas, 
pecados, que caracterizan a la sociedad del pasado pero, también, a la del presente. Esta forma narrativa entra en tensión con los discursos propios de la retórica deliberativa de Primo de Verdad, a través de los cuales se transmite un discurso independentista que tiende a oponer, en términos históricos el pasado en que dominaba la Iglesia, al periodo de la Reforma. La imagen del acontecer resulta aún más desestabilizada a partir de los discursos ambivalentes del narrador, que evidencian mucha mayor preocupación por el presente que por el pasado.

\section{La oveja descarriada vuelve al redil: Los piratas del Golfo}

A diferencia de las novelas anteriores, en Los piratas del Golfo, de Riva Palacio, ${ }^{14}$ no se observa ningún conflicto con la Inquisición o la Iglesia y ello favorece considerablemente la construcción de una narrativa que termina por conciliar los tiempos, a pesar de la oposición que se presenta inicialmente.

La novela se centra en Enrique de Torre Leal, un personaje que, a causa de algunas intrigas de su tío político, quien deseaba apoderarse de la herencia de la familia Torre Leal, perdió la gracia del virrey marqués de Mancera y se vio obligado a exiliarse a La Española. Ahí conoce a Juan Morgan, un pirata que aparece, en una primera instancia -y quizás haciendo eco del imaginario romántico del pirata como héroe libertario que difundieron obras como "La canción del pirata", de José de Espronceda-, como héroe que pretende liberar a América del dominio español. Esta novela lleva mucho más lejos que Guillén de Lampart las reflexiones en torno a los recursos violentos que implica una rebelión independentista, tal

${ }^{14}$ Esta novela fue publicada tres años antes de Memorias de un impostor. Sin embargo, no se respeta el orden cronológico en que el autor publicó sus novelas por razones expositivas: se buscó, en primer lugar, analizar las novelas que abordan los dos ejes temáticos que dirigen este estudio, el problema de la libertad y la oposición progreso y retroceso. A continuación se analizará una novela que solo retoma uno de esos temas. 
como se puede observar en los discursos del pirata Morgan cuando hace uso de la retórica deliberativa:

... cortar la comunicación entre Europa y sus colonias, destruir las armadas de sus opresores, animar con esto a los oprimidos, y ayudarles y aconsejarles la insurrección que sus dominadores no podrán sofocar ¿no es esto dar la libertad a medio mundo? ¿No es esto desencadenar cien naciones? Y para esto, es preciso comenzar de alguna manera, hoy como piratas, valiéndonos de la gente perdida, de los hombres que no van más que tras la codicia. Es preciso hacernos grandes y respetables por el terror, ya que somos pequeños por nuestros elementos; pero mañana, mañana, yo os lo aseguro, estos navíos piratas serán ya escuadras armadas, tan moralizadas como el mismo rey de España, y las aldeas de nosotros no temblarán de nosotros como de sus verdugos, sino que nos llamarán como a sus salvadores (1: 158-59).

No obstante lo impactante y persuasivo que puede resultar este discurso independentista, al grado de que el protagonista de la novela se involucra en el proyecto de Morgan, e incluso lo lidera por un tiempo, pronto se hace evidente que la revolución y la violencia constituyen el camino equivocado. En este mismo pasaje, Juan Morgan insinúa que, detrás de su proyecto se ocultan intereses personales: "hoy me apellidan pirata infame, mañana me bendecirán libertador, y más tarde me alzarán monumentos y me erigirán estatuas" (1: 159). Más adelante, Morgan cambia de personalidad sin que este cambio quede justificado por el desarrollo de la historia, olvida el proyecto independentista y se convierte en un pirata concupiscente que se emborracha y cuyo único pensamiento es tener relaciones sexuales con una mujer protegida por Enrique.

Este cambio de personalidad en los personajes ocurre frecuentemente en las novelas de Riva Palacio, las cuales tienden a yuxtaponer acontecimientos para desarrollar distintos temas que no se relacionan entre sí o, si se vinculan temáticamente, exponen por separado distintas facetas de un problema sin que se construya una 
relación lógica entre ellas. Es así que en la literatura de este autor predomina la casuística retórica.

En el caso de Los piratas del Golfo, se expone, en un primer momento, un intento de explicación de la independencia como acontecimiento revolucionario y violento, un tema latente en el imaginario de la República Restaurada, para el cual se acude a la narrativa romántica del héroe proscrito y rebelde que defiende un ideal, en este caso el pirata. ${ }^{15}$ En un segundo momento, se evidencia una actitud ambigua y desconfiada frente a ese tipo de héroes, a los que, como ocurre en Memorias de un impostor, se les atribuye una vanidad excesiva y ambiciones egoístas. Finalmente, se muestran las consecuencias nocivas que implican la asociación de cualquier actividad con la violencia y con personajes viciosos. Así es que Enrique termina por abandonar a Morgan para salvar a su protegida y decide volver a la Ciudad de México, donde al final se aclaran los malentendidos y Enrique regresa al seno de su sociedad.

La vida del protagonista está atravesada por tres tipos de narrativas: la novela heroica romántica, la novela de aventuras de prueba y la novela de educación. La primera aparece al inicio del relato, en una suerte de in medias res. Esta rige el periodo en que Enrique, exiliado, se enrola en la aventura de Morgan y trabaja por la independencia de América ante la convicción de las injusticias que se viven las colonias. En la segunda parte de la novela se ofrece una explicación del origen del personaje y los motivos que lo llevaron al exilio.

En ese momento se presenta una falta de correspondencia entre las causas del exilio -una intriga entre particulares en que se ve involucrada la autoridad- y los motivos que justifican el proyecto independentista -el dominio español sobre las colonias-, al grado de que la rebelión romántica del héroe termina pareciendo resultado

${ }^{15}$ La vigencia y el carácter problemático del tema se puede advertir, por ejemplo, en los distintos tratamientos de que es objeto Francisco Primo de Verdad. Mientras en Elpecado del siglo el personaje es aliado del gobierno, en el Libro rojo, Manuel Payno lo retrata como un conspirador y rebelde. 
de un equívoco que se resuelve satisfactoriamente, y, por tanto, el movimiento revolucionario en el que se involucra pierde legitimidad.

Casi al final de la novela asegura el marqués de Mancera: "los que mandamos estamos más expuestos a errar porque todos se empeñan en ocultarnos la verdad" (2: 234), y así el propio gobierno colonial es disculpado de los yerros motivados por las acciones de individuos corrompidos y ambiciosos. De la misma manera que ocurre en las otras novelas -y reafirmando la idea de que las preocupaciones de la República Restaurada se imponen sobre la representación del pasado y de los movimientos independentistas- son las acciones de ciertos miembros de la sociedad las que aparecen como responsables de las crisis, y no el gobierno en sí.

El conjunto de aventuras que enfrenta Enrique se inserta, además, en otro marco narrativo: la novela de pruebas. Estas desafían la integridad del héroe, una que viene marcada desde su apellido, Torre Leal. Una vez en el exilio, el personaje cambia de nombre y se hace llamar Brazo-de-Acero; bajo este apelativo, confirma su lealtad, fortaleza y honradez y, gracias a sus buenas acciones -entre ellas salvar a la esposa del Indiano de las garras de Morgan-, gana aliados que lo ayudan a probar su inocencia frente a las calumnias que derivaron en su exilio. De esta manera, Enrique puede recuperar su apellido y las posesiones de su condado, además de que el virrey acepta ser su padrino de bodas. De esta manera, se fortalecen los vínculos entre el individuo y la autoridad.

Si bien el protagonista tiende a reafirmar su identidad en la novela, también es cierto que experimenta ciertos cambios, y ahí es donde interviene la narrativa propia de la novela de educación. En un principio, el personaje se distingue por su carácter ligero y su falta de sagacidad en lo que se refiere a relaciones amorosas e interpersonales. Justamente es su ligereza la que lo lleva, sin él saberlo, a cortejar a una mujer casada, a tener conflictos con el Indiano y a exponerse a las calumnias de su tío político. En su exilio conoce el amor verdadero y el trabajo, descubre las razones de su exilio, conoce de cerca los vicios de los piratas, y ello lo convierte en un hombre más maduro, capaz de asumir el papel que le corresponde en la sociedad. Es así que, en lugar de cuestionarlo, al quedar enmarcados 
los discursos deliberativos y el relato independentista por otras formas narrativas más conservadoras, pareciera que la novela tiende a reafirmar un orden de mundo al que el individuo debe adecuarse.

Antes de concluir el análisis de la novela, cabe advertir que el desenlace del relato sugiere una interpretación alegórica que parece referirse alternativamente al presente y al pasado colonial: por un lado, Enrique es perdonado por el virrey, y así hay una reconciliación entre individuo y gobernante, necesaria para la paz pública. Asimismo, lima asperezas con el Indiano, un cacique noble que, en esta novela, parece representar el mundo indígena, un elemento particularmente problemático en el imaginario nacional, y la posibilidad de su convivencia pacífica de este último con el hombre de cultura occidental; de hecho, es el indígena el que intercede por Enrique ante el virrey. Además, la mujer que ama, y con la que se casa, es una joven de origen francés, de manera que se da la unión perfecta con la representante de una nación con la que México tuvo conflicto en los años previos a la República Restaurada, y esta unión se proyecta hacia el futuro. Finalmente, el ocupar el lugar que corresponde a Enrique como heredero del condado de Torre-Leal implica asumir su origen español. En lugar de un mensaje revolucionario, lo que parece predominar en esta novela es un mensaje de reconciliación. En este sentido, no parece gratuito que el único tema que no abarque es el de la Inquisición y lo que representaba en el contexto de la República Restaurada -retroceso, poder eclesiástico, conservadurismo-, tan dominante y problemático en otras novelas de Riva Palacio como Monja y casada, virgen y mártir, Martín Garatuza o Memorias de un impostor. Por su parte, desde una tendencia reconciliadora en torno a un orden de mundo particular, la independencia frente a España queda como un problema abierto, pero no resuelto por el relato.

\section{A manera de conclusión}

Como se puede advertir a partir de las novelas analizadas, en la representación del pasado colonial parecen intervenir de manera fundamental dos elementos: el contexto histórico en que fueron 
escritas las obras, que incide en la forma de abordar ciertos temas e imaginarios vinculados al pasado colonial, y los géneros literarios y discursivos de los que se alimentan las novelas para representar cada tema en particular y articularlo en un conjunto. Ambos elementos contribuyen a la conformación de un imaginario conflictivo y contradictorio sobre el pasado colonial.

Por un lado, el contexto de la República Restaurada, en que domina la preocupación por ordenar a la sociedad y consolidar un sistema político, parece influir considerablemente en la forma de figurar a los individuos y a los gobernantes. En las novelas nunca se pone en duda la legitimidad de los últimos; en contraste, los elementos conflictivos son los individuos que ambicionan y ponen en peligro el orden establecido. La narrativa costumbrista y didáctica, las novelas de educación y de pruebas, así como los relatos históricos ejemplares, se constituyen en formas discursivas que focalizan la atención en el individuo como problema; contribuyen a la representación de personajes que no se adecuan al orden establecido y deseado, o deben demostrar su valía para integrarse a él. Ello favorece la conformación de cierta relación empática con los gobernantes coloniales que hasta cierto punto matiza la oposición entre los tiempos que se fue instaurando en el imaginario desde los inicios del México independiente. No obstante, esta imagen de mundo deja sin explicación la independencia de México como un acontecimiento político, pues el elemento individual que interviene en esta última queda deslegitimado.

De manera paralela a lo anterior, se explora el tema de la necesidad de independencia en las dos vertientes que se fueron desarrollando en el imaginario del siglo XIX: como un acontecimiento político que implica la ruptura con España, y como una liberación frente al atraso que representaba la institución eclesiástica. En ambos, el conflicto se expresa fundamentalmente a través de los discursos de algunos personajes que echan mano de la retórica deliberativa y se presenta una falta de correspondencia entre los que los personajes revolucionarios dicen y lo que ocurre en las novelas, o lo que asevera el narrador, de manera que el discurso independentista no se incorpora de forma coherente en la narrativa del pasado. 
Llega a suceder, como en El pecado del siglo, que la independencia es vista como una mera transformación de las conciencias.

La vinculación entre imaginarios y géneros discursivos ayuda a evidenciar el carácter problemático y a veces contradictorio de la construcción narrativa del pasado, el cual se explica en función de las necesidades expresivas y las posibilidades de comprensión de un momento histórico determinado. Esta puede resultar una vía de análisis prometedora para lograr una comprensión más profunda de la conformación de los imaginarios sobre la historia nacional.

\section{Bibliografía}

Almazán, Pascual. Un hereje y un musulmán. La novela del México colonial, edición de Antonio Castro Leal, 4a. ed., tomo 2. Aguilar, 1979, pp. 847-970.

Altamirano, Ignacio Manuel. "Revistas literarias de México (18211867)". Obras completas xii. Escritos de literatura y arte, tomo 1, sep, 1988, pp. 29-174.

Araujo, Pardo, Alejandro. Novela, historia y lecturas. Usos de la novela histórica del siglo XIX mexicano: una lectura historiográfica. Universidad del Claustro de Sor Juana/ UAM, 2009.

Backzco, Bronislaw. Los imaginarios sociales. Memorias y esperanzas colectivas. Traducción de Pablo Batesh. Nueva Visión, 2005. Bajtín, Mijaíl. Estética de la creación verbal. Traducción de Tatiana Bubnova, 10a. ed., Siglo XXI, 1999.

- Teoría y estética de la novela. Trabajos de investigación. Traducción de Helena S. Kriúkova y Vicente Cazcarra. Taurus, 1989.

Berlin, Isaiah. Las raíces del romanticismo. Edición de Henry Ardí. Traducción de Silvina Marí. Taurus, 2000.

Bobadilla Encinas, Gerardo Francisco. "La poética de la novela histórica mexicana del siglo XIX: la historia y la cultura como testimonio mítico”. Tesis de doctorado. El Colegio de México, 2002. Booth, Wayne C. Retórica de la ficción. Traducción de Santiago Gubern Garriga-Nogués. Antoni Bosh, 1974. 
Brading, David. Los orígenes del nacionalismo mexicano. Traducción de Soledad Loaeza Grave. SepSetentas, 1973.

Castoriadis, Cornelius. La institución imaginaria de la sociedad. Traducción de Antoni Vicens. Tusquets, 1983, 2 tomos.

Chavarín, González, Marco Antonio. "Monja y casada, virgen y mártir y Martín Garatuza: una subordinación didáctica a las estructuras narrativas". Tesis inédita. unam, 2006.

Clark de Lara, Belem y Elisa Speckman Guerra, editoras. La República de las Letras. Asomos a la cultura escrita del México decimonónico. UNAM, 2005. 3 tomos.

Connaughton, Brian. Entre la voz de Dios y el llamado de la patria. Religión, identidad y ciudadanía en México, Siglo XIX. UAM/ FCE, 2010.

Cuéllar, José Tomás de. "La literatura nacional”. La misión del escritor. Ensayos mexicanos del siglo XIX. Coordinado por Jorge Ruedas de la Serna. UNAM, 1996. 215-21.

. El pecado del siglo. Novela histórica [Época de Revillagigedo-1789]. Obras I. Narrativa I. Edición, estudio preliminar, notas e índices de Belem Clark de Lara. UNAM, 2007.

Fernández de Lizardi, José Joaquín. Don Catrín de la Fachenda. Prólogo de Mariana Ozuna. Lectorum, 2001.

Fernández Prieto, Celia. Historia y novela: poética de la novela histórica. 2a. ed. Universidad de Navarra, 2003.

Genette, Gérard. Figures iii. Éditions du Seuil, 1972.

Guerra, François-Xavier. México: Del Antiguo Régimen a la Revolución. Traducción de Sergio Fernández Bravo, 2a. ed., tomo I. México: FCE, 1991.

Hale, Charles Adams. La transformación del liberalismo en México a fines del siglo XIX. Traducción de Purificación Jiménez. FCE, 2002.

Hernández Landa Valencia, Verónica. "Los tiempos de la historia: La representación de La Colonia en tres novelas históricas de la República Restaurada”. Tesis de doctorado. UNAM, 2014.

Jitrik, Noé. Historia e imaginación literaria. Las posibilidades de un género. Biblos, 1995. 
Knight, Alan. "El liberalismo mexicano desde la Reforma hasta la Revolución (una interpretación)". Historia Mexicana, vol. 35, no. 1, 1985, pp. 59-91.

López Martínez, María Isabel. El tópico literario: Teoría y crítica. Arco/Libros, 2007.

Lukács, Georg. La novela histórica. Traducción de Jasmin Reuter. 3a. ed. Era, 1977.

Moreno, Rafael. La filosofía de la Ilustración en México y otros escritos. UNAM, 2000.

O'Gorman, Edmundo. México: El trauma de su historia. Ducit amor patriae. Conaculta, 1999.

Ortiz Monasterio, José. Historia y ficción: Los dramas y novelas de Vicente Riva Palacio. Instituto de Investigaciones José María Luis Mora/ Universidad Iberoamericana, 1993.

México eternamente: Vicente Riva Palacio ante la escritura de la historia. México: Instituto de Investigaciones José María Luis Mora/ fce, 2004.

—. "Retórica, preceptiva literaria e historia en Vicente Riva Palacio". De la perfecta expresión. Preceptistas iberoamericanos del siglo XIX. Coordinado por Jorge Ruedas de la Serna. UNAM, 1998, pp. 178-189.

Pacheco, José Ramón. El criollo. La novela corta en el primer romanticismo mexicano. Edición de Celia Miranda Carabés. UNAM, 1998.

Pageaux, Daniel-Henri. "De la imaginería cultural al imaginario". Compendio de literatura comparada. Pierre Brunel e Yves Chevrel, directores. Traducción de I. Vericat Núñez. Siglo XXI Editores, 1994, pp 101-31.

Palti, Elias José. La invención de una legitimidad. Razón y retórica en el pensamiento mexicano del silgo XIX (Un estudio sobre las formas del discurso político). FCE, 2005.

Pani, Erika, coordinadora. Conservadurismo y derechas en la historia de México, tomo 1. FCE-Conaculta, 2009.

Payno, Manuel y Vicente Riva Palacio. El libro rojo. Conaculta, 2006. 
Pozuelo Yvancos, José María. "Retórica y narrativa: La narratio".

Epos. Revista de Filología, no. 2, 1986, pp. 231-252.

Pujante, David. Manual de retórica. Castalia, 2003.

Ramos, Julio. Desencuentros de la modernidad en América Latina.

Literatura y política en el siglo XIX. FCE, 1989.

Riva Palacio, Vicente. Memorias de un impostor. Don Guillén de Lampart, rey de México. Edición de Antonio Castro Leal. 4a. ed. Porrúa, 2000.

. Los piratas del Golfo. Edición de Antonio Castro Leal. 2a. ed. Porrúa, 1971.

Rodríguez Galván, Ignacio. "Profecía de Guatimoc". Poesía romántica. Selección de Alí Chumacero. Prólogo de José Luis Martínez. UNAM, 1993.

Ruedas de la Serna, Jorge, coordinador. La misión del escritor. Ensayos mexicanos del siglo XIX. UNAM, 1996.

Sierra O’Reilly, Justo. La hija del judío. Antonio Castro Leal, edición y prólogo. 2a. ed. 2 México: Porrúa, 1982. 2 tomos.

Sommer, Doris. Ficciones fundacionales. Las novelas nacionales de América Latina. Bogotá: FCE, 2004.

White, Hayden. "La poética de la historia". Metahistoria. La imaginación histórica en la Europa del siglo XIX. Traducción de Stella Mastrangelo. FCE, 2002, pp. 13-85.

Zea, Leopoldo. El pensamiento latinoamericano en el siglo XIX. Instituto Panamericano de Geografía e Historia, 1986. 